\title{
Perbincangan Bibliometrik 12 Tahun Penerbitan Jurnal Usuluddin (2000-2011)
}

\author{
Faisal @ Ahmad Faisal Abdul Hamid \\ Universiti Malaya, faisal@um.edu.my \\ DOI: https://doi.org/10.22452/usuluddin.vol47no1.4
}

\begin{abstract}
Abstrak
Artikel ini membincangkan penerbitan Jurnal Usuluddin selama 12 tahun, bermula pada tahun 2000-2011. Secara umumnya artikel ini mengandungi dua bahagian, yang pertama adalah berkaitan sejarah penerbitan jurnal di Universiti Malaya dan juga penerbitan jurnal di Akademi Pengajian Islam, UM dengan diikuti sejarah ringkas penerbitan Jurnal Usuluddin. Bahagian kedua membincangkan data-data berkaitan dengan penerbitan Jurnal Usuluddin secara bibliometrik. Antara perkara yang dianalisis ialah pola penulisan, institusi penulis, kekerapan penulisan, gander penulis serta bahasa artikel yang digunakan. Dari datadata yang diperolehi menunjukkan sepanjang tempoh penerbitan selama 12 tahun tersebut, Jurnal Usuluddin telah mengorak langkah ke hadapan untuk menjadikan ianya sebuah jurnal yang berwibawa dan antarabangsa. Usaha-usaha pembaharuan sentiasa berkembang bagi memperlengkapkan bidang kajian keilmuan Islam khususnya yang terkandung di dalam disiplin ilmu Usuluddin seperti Pengajian Al-Quran dan Al-Sunnah, Akidah, Falsafah, Dakwah, Pembangunan Ummah, Kepimpinan, Sejarah, Tamadun dan Peradaban Islam.
\end{abstract}

Kata kunci: Jurnal Usuluddin, kajian bibliometrik, penerbitan jurnal

\section{Years Bibliometric Discussion of Journal of Usuluddin Publishing (2000-2011)}

\section{Abstract}

This article discusses the publication of Journal of Usuluddin for 12 years, beginning in 2000-2011. Generally, this article contains two parts, the first one is about the history of publication journals at University of Malaya and the publication of journals at the Academy of Islamic Studies, UM with a brief history of publication the Journal of Usuluddin. The second part, discusses the data relating to the publishing of Journal of Usuluddin by bibliometric. Among the things analyzed were the writing pattern, the author's institute, the frequency of writing, the author's gander and the article language used. From the data obtained throughout the 12-year publication period, Journal of Usuluddin has taken a step forward to make it a credible and international journal. The reform efforts are constantly evolving to complement the field of Islamic scholarship, especially those contained in Usuluddin's disciplines such 
as Quranic Studies and al-Sunnah, Akidah, Philosophy, Da 'wah, Ummah Development, Leadership, History and Islamic Civilization.

Keywords: Journal of Usuluddin, bibliometric study, journal publication

\section{Pendahuluan}

Penghasilan karya oleh para ilmuwan menjadi salah satu kayu ukur kesarjanaan mereka, selain itu ianya juga dianggap sebagai amal soleh yang akan dibawa ke akhirat oleh para sarjana Islam. ${ }^{1}$ Karya ilmiah mereka itu akan diterbitkan oleh penerbit yang berwibawa sama ada dalam bentuk buku atau jurnal sebagai penghargaan kepada nilai ilmu yang dihasilkan. Manakala universiti sebagai sebuah institusi pendidikan tertinggi pastinya memainkan peranan utama untuk menghasilkan karya ilmiah yang bermutu dan diterbitkan dalam jurnal akademik yang berwibawa dengan keberadaan para ilmuwan di institusi tersebut, di samping universiti menjalankan tujuan lain seperti penyelidikan, pengajaran dan pembelajaran untuk melahirkan mahasiswa yang bermutu dan memberi khidmat kepada masyarakat. ${ }^{2}$ Kesemua itu selari dengan fungsi universiti untuk memartabatkan keilmuan dan menyumbang untuk manusia dan alam. Dalam konteks perbincangan ini, jurnal merupakan salah satu wacana ilmiah yang penting dalam penyebaran ilmu pengetahuan. Keperluan ahli akademik kepada jurnal lebih tertumpu kepada membentuk rangkaian dan ruang untuk berkolaborasi sesama mereka tentang hasil penyelidikan dan penemuan baru dalam bidang masingmasing, selain itu, jurnal juga menjadi tempat untuk masyarakat mendapat maklumat terkini dan sahih tentang sesuatu isu serta jawapan tuntas terhadap sesuatu persoalan dari pakar yang berkaitan. $^{3}$

Jurnal ilmiah ialah penerbitan yang mengandungi bahanbahan penulisan hasil penyelidikan atau kesarjanaan antara pakar-

\footnotetext{
Jalāl al-Dīn al-Suyūṭī, Al-Takrīf fì Adāb al-Ta'līf (Kaherah: Maktabah alThurath al-Islāmī, 1987), 18.

2 Ali Muhammad, Metode Penyelidikan Ilmiah (Bandung: Penerbitan Sakti, 1985), 13.

3 Ahmad Munawar Ismail, "Pembudayaan Ilmu Melalui Jurnal Akademik," laman sesawang Berita Harian Online, 30 Ogos 2018, dicapai 24 April 2019, https://www.bharian.com.my/rencana/komentar/2018/08/467756
} 
pakar, penyelidik, ahli akademik dalam bidang masing-masing. ${ }^{4}$ Perkataan jurnal merujuk kepada sebuah penerbitan berkala dalam bidang pengkhususan tertentu yang dikawal oleh piawai ilmiah. ${ }^{5}$ Hanya makalah yang bersifat asli dan memenuhi piawai sesebuah jurnal serta ditulis dalam laras bahasa ilmiah sahaja akan diterbitkan. Dengan kata lain, jurnal mempunyai editorial board yang mengawal mutu penerbitan jurnal ilmiah. ${ }^{6}$ Dengan penerbitan jurnal dan lain-lain penerbitan ilmiah perkembangan dan perkongsian ilmu dapat berlaku secara teratur dan berkesan. Para penyelidik dan ilmuwan mempunyai medium yang sesuai untuk saling berkongsi maklumat, penemuan dan permasalahan dalam bidang kajian masing-masing. ${ }^{7}$

Dalam sejarah penerbitan jurnal di Malaysia, jurnal tertua yang diterbitkan ialah Journal of Indian Archipelogi and Eastern Asia pada tahun 1847 di Singapura. Terdapat juga pandangan yang mengatakan bahawa jurnal Malay Magazine atau Bustan al- 'Arifin yang diterbitkan oleh C.H. Thomsen di Melaka pada 1820 adalah jurnal yang tertua di Malaysia. Dengan penerbitan dua jurnal tersebut sejak awal abad ke-19 lagi, memperlihatkan bahawa tradisi menerbitkan jurnal di Malaysia telah lama berakar umbi. Dalam legasi penerbitan itu, penerbitan jurnal ilmiah dalam bahasa Melayu masih dianggap baru, apatah lagi jurnal dalam bidang pengajian Islam. Selepas Kongres Bahasa Melayu Kedua di Singapura pada tahun 1956 barulah penerbitan bahan ilmiah dalam bahasa Melayu mula rancak dengan lahirnya Dewan Bahasa dan Pustaka (DBP) pada tahun yang sama. ${ }^{8}$

4 Md Sidin Ahmad Ishak, "Penerbitan Jurnal Ilmiah di Malaysia" (Prosiding Mapim 1: Penerbitan Jurnal Ilmiah di Malaysia, Universiti Malaya, 1997), 1.

5 Zainab Awang Ngah, "Malaysian Scholarly Journals: Their Visibility and Caracteristics," dalam Penerbitan Jurnal Ilmiah di Malaysia, ed. Md. Sidin Ahmad Ishal (Penyelenggara) (Kuala Lumpur: Penerbit Universiti Malaya, t..), 47.

6 Roosfa Hashim, “Pembangunan Jurnal Ilmiah Malaysia 1847-2007” (Kuala Lumpur Penerbit Universiti Malaya, 2011), 1.

7 Roosfa, “Pembangunan Jurnal Ilmiah Malaysia 1847-2007," 2.

8 Mohd Jajuli Abd. Rahman, "Penerbitan Jurnal: Pengalaman DBP” (Prosiding Mapim 1: Penerbitan Jurnal Ilmiah di Malaysia, Universiti Malaya, 1997), 7980 . 


\section{Sejarah Ringkas Penerbitan Jurnal di Universiti Malaya}

Antara faktor yang menjadi tumpuan utama kegiatan akademik para pensyarah, penyelidik dan mahasiswa di Universiti Malaya dan mana-mana universiti adalah penerbitan ilmiah. Universiti Malaya telah menerbitkan jurnal sejarah dengan nama The Historical Annual diterbitkan oleh Persatuan Sejarah Universiti Malaya Singapura seawal tahun 1952, dan setelah itu diikuti dengan penerbitan Journal of the Economics Society terbitan Universiti Malaya pada tahun 1960. ${ }^{9}$ Dalam tahun-tahun 1960-an, Penerbit Universiti Malaya lebih aktif dengan menerbitkan beberapa buah lagi jurnal seperti Journal of the Department of Engineering University of Malaya (1962), ${ }^{10}$ Malaysia Journal of Economic Studies (1964), ${ }^{11}$ dan Masalah Pendidikan pada (1965). ${ }^{12}$

Dalam tahun-tahun 1970-an, tiga buah jurnal baru telah diterbitkan, ianya memperlihatkan bidang penyelidikan semakin berkembang di Universiti Malaya khususnya dalam bidang sejarah. Jurnal tersebut ialah Jernal Sejarah pada tahun $(1975)^{13}$ dan Jernal Pentadbir (1978) ${ }^{14}$ selain Jurnal Pengajian Asia Tenggara (1979). ${ }^{15}$ Sekitar tahun 1980-an, berlaku pertambahan yang ketara dalam penerbitan karya akademik di Universiti Malaya antaranya penerbitan ISLAMIKA (1981), ${ }^{16}$ Sarjana (1981), ${ }^{17}$ Jurnal Bahasa Moden (1983), ${ }^{18}$ Jurnal Pengajian India

9 Journal of the Economic Society (Kuala Lumpur: Penerbit Universiti Malaya, 1960).

10 Journal of the Department of Engineering University of Malaya (Kuala Lumpur: Jabatan Kejuruteraan Universiti Malaya, 1962).

11 Malaysia Journal of Economic Studies (Kuala Lumpur: Fakulti Ekonomi dan Pentadbiran Universiti Malaya, 1964).

12 Masalah Pendidikan (Kuala Lumpur: Fakulti Pendidikan Universiti Malaya, 1965).

13 Jernal Sejarah (Kuala Lumpur: Jabatan Sejarah Universiti Malaya, 1975).

14 Jernal Pentadbir (Kuala Lumpur: Kelab Pentadbiran Awam, Fakulti Ekonomi dan Pentadbiran Universiti Malaya, 1978).

15 Jurnal Pengajian Asia Tenggara (Kuala Lumpur: Jabatan Pengajian Asia Tenggara Universiti Malaya, 1979).

16 ISLAMIKA (Kuala Lumpur: Akademi Islam Universiti Malaya, 1981).

17 Sarjana (Kuala Lumpur: Fakulti Sastera dan Sains Sosial Universiti Malaya, 1981).

18 Jurnal Bahasa Moden (Kuala Lumpur: Pusat Bahasa Universiti Malaya, 1983). 
(1983), ${ }^{19}$ Jurnal Pendidikan Islam (1984), ${ }^{20}$ Berita Kejuruteraan (1987), ${ }^{21}$ Sejarah: Jurnal Jabatan Sejarah Universiti Malaya (1988), ${ }^{22}$ MEDIUM: Majalah Elmiah $(1988)^{23}$ dan Jurnal Pengajian Melayu (1989). ${ }^{24}$

Tahun 1990-an menunjukkan penerbitan karya akademik baru seperti Majalah Pengajian Arab (1990), Jurnal Syariah (1993), ${ }^{25}$ Jurnal Usuluddin (1993), ${ }^{26}$ Tirai Panggung (1993), ${ }^{27}$ Jurnal Jabatan Pengajian Asia Tenggara Universiti Malaya (1995) ${ }^{28}$ Journal of University of Malaya Medical Centre (1996), Jurnal Pengajian Media Malaysia (1998). Pada tahun desawarsa 2000, perkembangan penerbitan jurnal-jurnal di Universiti Malaya makin rancak berkembang antaranya Journal of Problem-Based Learning (2003), Jurnal Al-Bayan (2003) ${ }^{29}$, Jurnal Figh (2004) ${ }^{30}$, Jurnal Al-Tamaddun (2005), ${ }^{31}$ International Journal of Mechanical and Materials Engineering (2006), ${ }^{32}$ Asian Journal of

19 Jurnal Pengajian India (Kuala Lumpur: Jabatan Pengajian India Universiti Malaya, 1983).

20 Jurnal Pendidikan Islam (Kuala Lumpur: Fakulti Pendidikan Universiti Malaya,1984).

21 Berita Kejuruteraan (Kuala Lumpur: Fakulti Kejuruteraan Universiti Malaya, 1987).

22 Sejarah: Jurnal Jabatan Sejarah Universiti Malaya (Kuala Lumpur: Jabatan Sejarah, Fakulti Sastera dan Sains Sosial, 1988).

${ }^{23}$ MEDIUM:Majalah Elmiah (Kuala Lumpur: Akademi Islam Universiti Malaya, 1988).

24 Jurnal Pengajian Melayu (Kuala Lumpur: Akademi Pengajian Melayu Universiti Malaya, 1989).

25 Jurnal Syariah (Kuala Lumpur: Fakulti Syariah Universiti Malaya, 1993).

26 Jurnal Usuluddin (Kuala Lumpur: Fakulti Usuluddin Universiti Malaya, 1993).

27 Tirai Panggung (Kuala Lumpur: Pusat Kebudayaan Universiti Malaya, 1993).

28 Jurnal Jabatan Pengajian Asia Tenggara Universiti Malaya (Kuala Lumpur: Jabatan Pengajian Asia Tenggara Universiti Malaya, 1995).

29 Jurnal Al-Bayan (Kuala Lumpur: Jabatan Al-Quran dan Al-Hadith Akademi Pengajian Islam Universiti Malaya, 2003).

30 Jurnal Fiqh (Kuala Lumpur: Jabatan Fiqh dan Usul, Akademi Pengajian Islam Universiti Malaya, 2004).

31 Jurnal Al-Tamaddun (Kuala Lumpur: Jabatan Sejarah dan Tamadun Islam, Akademi Pengajian Islam Universiti Malaya, 2005).

32 International Journal of Mechanical and Materials Engineering (Kuala Lumpur: Jabatan Kejuruteraan Mekanikal Universiti Malaya, 2006). 
Business and Accounting (2008), ${ }^{33}$ Jurnal Peradaban (2008), ${ }^{34}$ dan Jurnal al-Muqaddimah (2013). ${ }^{35}$ Jika dilihat kepada produktiviti jurnal ilmiah yang diterbitkan oleh Penerbit Universiti menunjukkan bahawa Universiti Malaya telah menerbitkan tidak kurang dari 40 buah jurnal ilmiah sejak judul jurnal yang pertama diterbitkan hingga penghujung tahun 2013. Begitu juga penerbitan jurnal ilmiah ini selaras dengan penubuhan fakulti atau jabatanjabatan yang baru diwujudkan. ${ }^{36}$

\section{Penerbitan Jurnal Awal di Akademi Pengajian Islam, Universiti Malaya}

Seperti yang telah dibincangkan di atas, institusi pendidikan tinggi dan penulisan karya ilmiah sangat berkait rapat antara sama lain. Ini kerana apabila dilihat kepada penubuhan fakulti terawal di Universiti Malaya seiring dengan penghasilan karya ilmiah dalam bentuk artikel dalam jurnal. Keadaan yang sama berlaku kepada perkembangan karya ilmiah di Akademi Pengajian Islam, Universiti Malaya dilihat seiring dengan penghasilan penerbitan jurnal atau karya ilmiah melalui Penubuhan Akademi Islam, Universiti Malaya pada 1 April $1981^{37}$ selari dengan penerbitan, Jurnal ISLAMIKA juga lahir pada tahun 1981 untuk penerbitan bilangan yang pertama.

Pada hari ini, penerbit-penerbit universiti giat menjalankan penerbitan bahan-bahan ilmiah baik berbentuk buku, majalah ilmiah, prosiding seminar, jurnal ilmiah. Jika penerbitan karya ilmiah berlaku seiring dengan penubuhan sesebuah fakulti atau jabatan, keadaan ini juga dilihat sama dengan sejarah perkembangan karya ilmiah yang berlaku di Akademi Pengajian Islam, Universiti Malaya. Perkembangan penulisan ilmiah bukan sahaja berlaku di peringkat penerbit universiti bahkan terbitan-

33 Asian Journal of Business and Accounting (Kuala Lumpur: Fakulti Perniagaan dan Perakaunan Universiti Malaya, 2008).

34 Jurnal Peradaban (Kuala Lumpur: Pusat Dialog Peradaban Universiti Malaya, 2008).

35 Jurnal Al-Mukaddimah (Kuala Lumpur: Jabatan Sejarah dan Tamadun Islam, Akademi Pengajian Islam Universiti Malaya, 2013).

36 Faisal@ Ahmad Faisal bin Abdul Hamid dan Saudah, "Sejarah Penerbitan Empat Jurnal Awal di APIUM," Jurnal al-Tamaddun 10 (1). (2015), 79.

37 "Sejarah Ringkas Penubuhan Jabatan," laman sesawang Jabatan Akidah dan Pemikiran Islam, dicapai 13 Mei 2019, http://japi-apium.blogspot.com/ 
terbitan ilmiah berlaku di peringkat yang lebih kecil seperti di peringkat jabatan dan fakulti seperti Jabatan Pengajian Islam, Akademi Islam Universiti Malaya, jabatan ini adalah sebuah jabatan yamg proaktif dalam menghasilkan produktiviti karya ilmiah malah ianya menjadi pelopor utama kepada penerbitan ilmiah yang berlaku di Fakulti Syariah dan Fakulti Usuluddin, Akademi Islam, Universiti Malaya untuk penerbitan-penerbitan selepasnya.

Mendahului penerbitan ilmiah awal di APIUM, dua buah jurnal secara relatifnya telah diterbitkan, pertamanya prior kepada bidang kajian Syariah melalui penerbitan jurnal ISLAMIKA dan penerbitan kedua diberi nama majalah MEDIUM.

\section{Sekilas Tentang Jurnal Usuluddin}

Jurnal usuluddin merupakan salah satu jurnal bidang pengajian Islam yang telah diterbitkan oleh Akademi Pengajian Islam, Universiti Malaya. Pada tahun 2019, usia penerbitan Jurnal Usuluddin telah mencecah 26 tahun setelah penerbitan pertamanya diterbitkan pada tahun 1993. Aspek perbincangan yang terdapat dalam Jurnal Usuluddin berkaitan dengan pengajian Akidah dan Pemikiran Islam, pengajian al-Quran dan al-Hadith, Dakwah dan Pembangunan Insan serta Sejarah dan Tamadun Islam. Setelah keempat-empat bidang pengajian tersebut berkembang selari dengan perkembangan zaman, kini, bidang pengajian al-Quran dan al-Hadith telah menerbitkan jurnal yang tersendiri dengan nama al-Bayan (2000), tiga tahun selepas itu bidang pengajian akidah dan pemikiran Islam pula menerbitkan jurnal bernama al-Afkar (2003) dan diikuti dengan bidang pengajian sejarah dan tamadun Islam dua buah jurnal iaitu al-Tamaddun (2005) dan alMuqaddimah (2013). Hanya bidang pengajian dakwah dan pembangunan insan sahaja sehingga kini tidak mempunyai jurnal tersendiri.

Jurnal Usuluddin menggunakan tiga bahasa iaitu bahasa Melayu, Inggeris dan Arab. Oleh kerana kebanyakan penulis artikel terdiri dari penutur bahasa Melayu hampir 77\% artikel yang telah diterbitkan dalam bahasa Melayu, diikuti dengan bahasa Inggeris dan Arab. Kemungkinan penggunaan bahasa Melayu yang begitu ketara dalam penerbitan Jurnal Usuluddin adalah 
untuk bacaan para mahasiswa di Universiti Malaya dan universiti tempatan yang kebanyakan berbahasa Melayu.

Penerbitan Jurnal Usuluddin merupakan antara jurnal terawal bidang Usuluddin yang telah diterbitkan oleh Bahagian Pengajian Islam, Akademi Islam Universiti Malaya (AIUM) seawal tahun 1993 lagi. Namun begitu, bermula tahun 1996, hak penerbitan Jurnal Usuluddin kemudian telah bertukar dan diambil alih oleh Fakulti Usuluddin, Akademi Pengajian Islam Universiti Malaya (APIUM) dan sekali lagi kuasa penerbitan Jurnal Usuluddin berubah dan diambil alih oleh Bahagian Pengajian Islam, Akademi Pengajian Islam Universiti Malaya (APIUM) pada tahun 2011. Sekali lagi pada tahun 2013, hak penerbitan Jurnal Usuluddin dipegang oleh Akademi Pengajian Islam Universiti Malaya (APIUM).

Mengenai sejarah penerbitannya pula, walaupun keluaran pertama telah diterbitkan pada 1993, namun pada tahun 1994 tiada keluaran yang ditemui, mungkin disebabkan oleh masalah pengurusan maka pada tahun itu keluaran kedua terbantut. Pada tahun ketiga, 1995, jurnal Usuluddin terbitkan dengan kekerapan dwi tahunan, dimulai dengan bil.2 dan 3 pada tahun 1995. Sejak itu, Jurnal Usuluddin diterbitkan pada bulan Jun dan Disember setiap tahun. Kekerapan dwi tahunan itu terbantut sekali lagi pada bil.23-24 tahun 2006. Pada ketika itu pengurus jurnal ialah Dr Mahmud dari Jabatan Akidah dan Pemikiran Islam. Hingga keluaran Vol.46, bil.2 2018, sebanyak 47 buah keluaran telah diterbitkan.

Antara sidang editor yang banyak menyumbangkan jasa dalam menjayakan penerbitan Jurnal Usuluddin ini adalah para ahli akademik di Bahagian Usuluddin sendiri yang berperanan menyumbang pelbagai bentuk yakni dalam bentuk sumbangan artikel, pandangan, cetusan pendapat, sumber tenaga kerja dan manusia juga masa. Antara Ketua Editor yang banyak berjasa dalam menyempurnakan terbitan jurnal ini ialah Wan Yahya Wan Ahmad (1993), Ab. Aziz Mohd Zin (1995), Mohd Kamil Hj. Abd Majid (1996-2009) diikuti pula oleh Wan Suhaimi Wan Abdullah (2010-2012) manakala kini sidang editorial dipimpin oleh Mustaffa Abdullah dari Jabatan al-Quran dan al-Hadith.

Penerbitan jurnal ini sekaligus digunakan sebagai medium diskusi para penyelidik dalam menyampaikan hasil kajian dan 
cetusan pandangan melalui terbitan jurnal ini. Jurnal Usuluddin juga dijadikan jurnal rasmi rasmi bagi kursus Pengajian Sarjana Muda Usuluddin di Akademi Pengajian Islam Universiti Malaya. Menggunakan Bahasa Melayu, Inggeris dan Arab sebagai bahasa pengantar utama dalam penerbitan jurnal ilmiah sebagai medium penyampaian maklumat berbentuk tulisan.

\section{Metodologi Kajian}

Kajian ini hanya memilih sampel penerbitan Jurnal Usuluddin dari tahun 2000, vo.11 hingga tahun 2011, vo.34. iaitu selama 12 tahun penerbitan yang merangkumi 23 keluaran. Sebanyak 362 orang penulis sama ada penulis tunggal atau penulis bersama, dan sebanyak 248 artikel dari keseluruhan keluaran selama tempoh 2000-2011. Data-data ini diperolehi dari Jurnal Usuluddin yang terdapat dalam simpanan koleksi terhad di Perpustakaan Akademi Pengajian Islam, Universiti Malaya dan dibuat semakan kedua dari edisi online yang terdapat di website jurnal-jurnal Universiti Malaya yang menempatkan Jurnal Usuluddin di alamat https://ejournal.um.edu.my/index.php/JUD/.

Untuk menganalisis data kajian pula, kajian ini membahagikan analisis kepada (1) penulis, (2) gender, (3) tahun terbitan, (4) bilangan kepenulisan, (5) nama institusi, (6) nama negara, (7) bilangan halaman serta (8) penggunaan bahasa. Maklumat kemudian dianalisis menggunakan Statistical Product and Service Solution (SPSS) yang mana pengkaji menganalisis data menggunakan Descriptive Statistics bagi mendapatkan keputusan kajian. Pengkaji juga menggunakan Descriptive Analysis dalam menentukan taburan bentuk atau pola Penulis, gender Penulis, Penulis prolifik, kekerapan bilangan halaman, kekerapan panjang artikel, jabatan tempat Penulis bertugas dan institusi tempat Penulis bertugas, demikian juga dari universiti mana dalam mengukur kekerapan, begitu juga negara asal penulis dan kekerapan penggunaan bahasa. Analisis dibentangkan dalam bentuk jadual.

\section{Data Kajian}

Data-data yang dipaparkan di bawah adalah dari penerbitan Jurnal Usuluddin selama 12 tahun bermula dari 2000-2011. Dalam tempoh tersebut terdapat 23 keluaran walaupun ianya diterbitkan 
secara dwi-tahunan kerana pada tahun 2006, hanya satu keluaran sahaja yang diterbitkan iaitu bil. 23-24.

Jadual 1: Bilangan dan Panjang Artikel

\begin{tabular}{|c|c|c|c|c|c|}
\hline Tahun & $\begin{array}{c}\text { Bil. } \\
\text { Artikel }\end{array}$ & $\begin{array}{c}\text { Jumlah } \\
\text { Halaman }\end{array}$ & $\begin{array}{c}\text { Purata } \\
\text { Halaman }\end{array}$ & $\begin{array}{c}\text { Bil. } \\
\text { Penulis }\end{array}$ & $\begin{array}{c}\text { Peratus } \\
(\%)\end{array}$ \\
\hline 2000 & 26 & 382 & 15 & 29 & 8 \\
\hline 2001 & 22 & 337 & 15 & 24 & 6.6 \\
\hline 2002 & 22 & 406 & 18 & 25 & 6.9 \\
\hline 2003 & 27 & 436 & 16 & 35 & 9.7 \\
\hline 2004 & 26 & 498 & 19 & 34 & 9.4 \\
\hline 2005 & 14 & 331 & 24 & 24 & 6.6 \\
\hline 2006 & 12 & 280 & 23 & 15 & 4.1 \\
\hline 2007 & 20 & 371 & 19 & 25 & 6.9 \\
\hline 2008 & 23 & 399 & 17 & 44 & 12.2 \\
\hline 2009 & 28 & 703 & 25 & 44 & 12.2 \\
\hline 2010 & 15 & 417 & 28 & 31 & 8.7 \\
\hline 2011 & 13 & 300 & 23 & 32 & 8.8 \\
\hline Jumlah & 248 & 4860 & 20 & 362 & 100 \\
\hline
\end{tabular}

Jadual 1. Menunjukkan bilangan dan panjang artikel dalam Jurnal Usuluddin sepanjang tahun 2000-2011. Berdasarkan jadual di atas, jumlah penerbitan Jurnal Usuluddin 2000-2011 adalah berjumlah 23 kali terbitan merangkumi 248 buah artikel yang ditulis oleh 362 orang penulis. Jadual juga menunjukkan jumlah artikel tertinggi adalah pada tahun 2009 iaitu sebanyak 28 buah artikel (11.0\%) manakala jumlah artikel terendah adalah pada tahun 2006 berjumlah 12 buah artikel (5.0\%). Bagi jumlah muka surat setiap artikel pula, bilangan tertinggi dalam setiap keluaran juga berlaku pada penerbitan Jurnal Usuluddin tahun 2009 dengan jumlah 703 muka surat. Manakala jumlah muka surat terendah dalam keluaran jurnal ini juga pada tahun 2006 hanya 280 muka surat. Purata bagi jumlah keseluruhan muka surat dalam Jurnal Usuluddin 2000-2011 adalah sekitar 20 muka surat bagi setiap artikel. Begitu juga jika dilihat kepada bilangan penulis artikel Jurnal Usuluddin sepanjang tahun 2000-2011 menunjukkan bahawa tahun 2008 dan 2009 mencatatkan jumlah penulis artikel tertinggi dengan masing-masing berjumlah 44 orang penulis, iaitu sebanyak (12.0\%) manakala jumlah penulis terendah adalah pada tahun 2006 mencatatkan jumlah 15 orang penulis sahaja, iaitu $(4.0 \%)$. 
Jadual 2: Pola Penulis

\begin{tabular}{|c|c|c|c|c|c|c|c|c|c|c|c|c|c|}
\hline $\begin{array}{l}\text { Pola } \\
\text { Penulis }\end{array}$ & 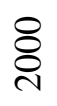 & ఠ్ & §̊̊ి & ڤి & d & 站 & ¿্ণ & 용 & $\stackrel{\infty}{\stackrel{2}{ి}}$ & ஓे & $\begin{array}{l}0 \\
\stackrel{\lambda}{\sim}\end{array}$ & $\overline{\bar{\sigma}}$ & $\begin{array}{l}\text { Jumlah } \\
\text { Artikel }\end{array}$ \\
\hline 1 & 23 & 20 & 19 & 20 & 20 & 7 & 9 & 15 & 8 & 15 & 1 & 2 & 159 \\
\hline 2 & 3 & 2 & 3 & 6 & 5 & 6 & 3 & 5 & 11 & 11 & 12 & 4 & 71 \\
\hline 3 & 0 & 0 & 0 & 1 & 0 & 0 & 0 & 0 & 2 & 1 & 2 & 6 & 12 \\
\hline 4 & 0 & 0 & 0 & 0 & 1 & 0 & 0 & 0 & 2 & 1 & 0 & 1 & 5 \\
\hline 5 & 0 & 0 & 0 & 0 & 0 & 1 & 0 & 0 & 0 & 0 & 0 & 0 & 1 \\
\hline Jumlah & 26 & 22 & 22 & 27 & 26 & 14 & 12 & 20 & 23 & 28 & 15 & 13 & 248 \\
\hline
\end{tabular}

Jadual 2 menunjukkan pola penulis dalam Jurnal Usuluddin sepanjang penerbitan 2000-2011 lebih kepada penulis tunggal. Pola penulis dalam jadual di atas boleh dibahagikan kepada lima pola iaitu pola penulis tunggal, penulis berdua, penulis bertiga, penulis berempat dan penulis berlima. Pola penulis secara individu atau tunggal mencatatkan jumlah artikel tertinggi dengan jumlah 159 buah artikel (64.0\%), manakala pola penulis secara berdua mencatatkan jumlah artikel kedua tertinggi berjumlah 71 buah artikel (28.6\%). Diikuti penulis secara bertiga di kedudukan yang ketiga dengan bilangan artikel berjumlah 12 buah artikel (4.8\%).

Bagi pola penulis secara berempat dan pola penulis secara berlima masing-masing mencatatkan jumlah bilangan artikel sebanyak 5 buah artikel (2.0\%) dan sebuah artikel sahaja (0.4\%) bagi pola penulis berlima. Berdasarkan paparan pola penulis dalam jadual di atas menunjukkan bahawa pola penulis secara individu lebih digemari dalam penulisan artikel berbanding dengan bentuk pola penulis yang lain terutama berlima. Kenyataan ini turut diakui oleh Mustaffa Abdullah dalam hasil temu bual mengatakan beliau lebih suka menulis secara individu ${ }^{38}$ melainkan artikel yang ditulis itu adalah hasil dari penyelidikan bersama di kalangan ahli-ahli akademik. Mungkin budaya menulis secara sendirian adalah budaya penulisan ulama Islam silam yang hanya mengarang karya mereka secara sendirian menjadi ikutan atau ukuran yang diterima pakai dalam Pengajian Islam khususnya Pengajian Usuluddin.

38 Mustaffa Abdullah (Pensyarah, Jabatan al-Quran dan al-Hadith, Akademi Pengajian Islam Universiti Malaya), dalam temubual dengan penulis pada 23 Ogos 2017. 
Jadual 3: Gender Penulis

\begin{tabular}{|c|c|c|}
\hline Gender & Bil. Penulis & Peratus (\%) \\
\hline Lelaki & 272 & 75.0 \\
\hline Perempuan & 90 & 25.0 \\
\hline Jumlah & 362 & 100 \\
\hline
\end{tabular}

Jadual 3. pula menunjukkan kekerapan penyumbang artikel berasaskan gender sepanjang tahun 2000-2011. Secara keseluruhan, jumlah penulis artikel dalam Jurnal Usuluddin adalah seramai 362 orang terdiri daripada penulis lelaki dan perempuan. Berdasarkan jadual di atas, dapat dilihat bahawa jumlah penulis lelaki lebih dominan berbanding dengan jumlah penulis perempuan melebihi tiga kali ganda daripada jumlah keseluruhan bilangan penulis Jurnal Usuluddin. Sumbangan artikel oleh penulis lelaki sebanyak 272 artikel, menyamai (75.0\%). Sebaliknya penulis perempuan hanya seramai 90 orang penulis sahaja, menyamai $(25.0 \%)$ dari keseluruhan penulis. Jika diteliti kekerapan penulis lelaki dalam menyumbang artikel kepada Jurnal Usuluddin, ianya menunjukkan bahawa lelaki lebih dominan berbanding penulis perempuan pada setiap tahun. Namun begitu, selepas tahun 2007, penglibatan penulis perempuan semakin bertambah dalam menyumbangkan hasil penulisan mereka dalam Jurnal Usuluddin. Jumlah Penulis lelaki diihat lebih tinggi dari penulis perempuan mungkin kerana bilangan pensyarah lelaki di APIUM lebih ramai dari bilangan pensyarah perempuan.

Jadual 4: Jumlah Halaman Artikel

\begin{tabular}{|c|c|c|}
\hline Jumlah Hal. & Bil. Artikel & Peratus (\%) \\
\hline $01-10$ & 11 & 4.4 \\
\hline $11-20$ & 120 & 48.4 \\
\hline $21-30$ & 95 & 38.3 \\
\hline $31-40$ & 17 & 6.9 \\
\hline $41-50$ & 4 & 1.6 \\
\hline $51-60$ & 1 & 0.4 \\
\hline Jumlah & 248 & 100 \\
\hline
\end{tabular}

Jadual. 4 menunjukkan nisbah jumlah halaman artikel dalam Jurnal Usuluddin sepanjang tahun 2000-2011. Terdapat enam corak kekerapan jumlah halaman artikel yang dipamerkan iaitu jumlah halaman artikel 1-10, jumlah halaman artikel 11-20, jumlah halaman artikel 21-30, jumlah halaman artikel 31-40, jumlah halaman artikel 41-50 dan jumlah halaman artikel 51-60. 
Dari analisis keseluruhan, jumlah halaman tertinggi sesebuah artikel dalam Jurnal Usuluddin adalah dari halaman 11-20 dengan jumlah 120 buah artikel (48.4\%). Manakala jumlah halaman artikel terendah adalah sekitar 51-60 dengan jumlah 1 buah artikel $(0.4 \%)$.

Bagi lain-lain jumlah halaman artikel yang sering ditulis oleh kebanyakan penulis artikel antaranya jumlah halaman artikel dari 21-30 halaman antara kedua tertinggi dengan jumlah 95 buah artikel (38.3\%) dan diikuti dengan jumlah halaman artikel dari 3140 halaman dengan jumlah 17 buah artikel (6.9\%). Manakala bagi jumlah halaman artikel dari 1-10 dan jumlah halaman artikel sekitar 41-50 halaman agak rendah berbanding dengan jumlah halaman artikel yang lain dengan masing-masing menyumbang 11 buah artikel (4.4\%) dan 4 buah artikel sahaja (1.6\%).

Berdasarkan jumlah halaman artikel tertinggi iaitu sekitar 1120 muka surat bukan sahaja menjadi pilihan kebanyakan ahli akademik untuk menulis karya mereka, sebaliknya ianya juga merupakan syarat yang telah ditetapkan oleh editor jurnal bagi setiap artikel yang dihasilkan.

Jadual 5: Jumlah Artikel oleh Penulis

\begin{tabular}{|c|c|c|c|c|}
\hline No. & Nama Penulis & $\begin{array}{c}\text { Jumlah } \\
\text { Per } \\
\text { Orang }\end{array}$ & Jumlah & $\begin{array}{c}\text { Peratus } \\
(\%)\end{array}$ \\
\hline 1. & Che Zarrina Sa'ari & 15 & 15 & 4.1 \\
\hline 2. & Joni Tamkin Borhan & 13 & 13 & 3.6 \\
\hline 3. & Mohd Fauzi Hamat & 10 & 10 & 2.8 \\
\hline \multirow{2}{*}{4.} & Khadijah Mohd Hambali & 9 & \multirow{2}{*}{18} & \multirow{2}{*}{5.0} \\
\hline & Zulkifli Mohd Yusoff & 9 & & \\
\hline 5. & Wan Suhaimi Wan Abdullah & 8 & 8 & 2.2 \\
\hline \multirow{2}{*}{6.} & Ab. Aziz Mohd Zin & 6 & \multirow{2}{*}{12} & \multirow{2}{*}{3.4} \\
\hline & Mahmud Ahmad & 6 & & \\
\hline \multirow{6}{*}{7.} & Faizuri Abd Latif & 5 & \multirow{6}{*}{30} & 1.4 \\
\hline & Mohd Roslan Mohd Nor & 5 & & 1.4 \\
\hline & Yusmini Yusoff & 5 & & 1.4 \\
\hline & Badlihisham Mohd Nasir & 5 & & 1.4 \\
\hline & Ahmad Faisal Abdul Hamid & 5 & & 1.4 \\
\hline & Mohd Kamil Ab Majid & 5 & & 1.4 \\
\hline 8. & 4 orang penulis & 4 & 16 & 4.4 \\
\hline 9. & 8 orang penulis & 3 & 24 & 6.6 \\
\hline
\end{tabular}




\begin{tabular}{|c|l|c|c|c|}
\hline No. & \multicolumn{1}{|c|}{ Nama Penulis } & $\begin{array}{c}\text { Jumlah } \\
\text { Per } \\
\text { Orang }\end{array}$ & Jumlah & $\begin{array}{c}\text { Peratus } \\
(\%)\end{array}$ \\
\hline 10. & 35 orang penulis & 2 & 70 & 19.3 \\
\hline 11. & 146 orang penulis & 1 & 146 & 40.3 \\
\hline & Jumlah & & 362 & 100 \\
\hline
\end{tabular}

Jadual 5 menunjukkan kekerapan penghasilan artikel oleh penulis-penulis dalam Jurnal Usuluddin sepanjang tahun 20002011. Berdasarkan jadual di atas, Che Zarrina Sa'ari menduduki tangga penulis paling prolifik dengan jumlah artikel tertinggi iaitu 15 buah artikel (4.1\%). Seterusnya penulis prolifik kedua iaitu Joni Tamkin Borhan dengan jumlah 13 buah artikel (3.6\%). Penulis paling banyak ketiga pula, ialah Mohd Fauzi Hamat dengan jumlah sumbangan 10 buah artikel (2.8\%). Manakala Khadijah Mohd Khambali @ Hambali dan Ya'kub @ Zulkifli Mohd Yusoff masing-masing menyumbang 9 buah artikel (2.5\%) menjadikan jumlah kekerapan bagi kedua-dua penulis ini berjumlah 18 buah artikel (5.0\%). Di belakang mereka berdua pula, Wan Suhaimi Wan Abdullah dengan jumlah 8 buah artikel $(2.2 \%)$.

Ab. Aziz Mohd Zin dan Mahmud Ahmad masing-masing menyumbang 6 buah artikel (1.7\%) menjadikan jumlah kekerapan artikel yang disumbangkan oleh kedua-dua penulis ini berjumlah 12 buah (3.4\%). Selain itu, enam orang penulis prolifik yang terdiri dari Faizuri Abd Latif, Faisal @ Ahmad Faisal Abdul Hamid, Mohd Roslan Mohd Nor, Badlihisham Mohd Nasir, Yusmini Yusoff dan Mohd Kamil Abd. Majid masing-masing menyumbang 5 buah artikel (1.5\%) menjadikan jumlah keseluruhan artikel bagi 6 Penulis ini berjumlah 30 buah artikel $(8.3 \%)$.

Manakala bagi sumbangan 4 buah artikel dalam Jurnal Usuluddin melibatkan 4 orang penulis menjadikan jumlah artikel bagi keempat-empat penulis adalah 16 buah (4.4\%). Seterusnya, bagi nilai 3 buah artikel melibatkan 8 orang penulis menjadikan jumlah artikel bagi kelapan-lapan penulis adalah 24 buah artikel (6.6\%). Bagi nilai 2 buah artikel dalam jurnal disumbangkan oleh 35 orang penulis menjadikan jumlah keseluruhan adalah 70 buah artikel $(19.3 \%)$. Sementara bagi nilai 1 buah artikel $(0.3 \%)$ 
melibatkan 146 orang Penulis menjadikan jumlah keseluruhan adalah 146 buah artikel (40.3\%).

Hampir setiap tahun, Che Zarrina Sa'ari terlibat menyumbang artikel dalam Jurnal Usuluddin sejak tahun 2007 lagi bagi penerbitan Jurnal Usuluddin bilangan ke-7 (1997). ${ }^{39}$ Pada tahun 2000, beliau telah menyumbang dua buah artikel dalam Jurnal Usuluddin bilangan ke-11 dan Jurnal Usuluddin bilangan ke-12, tajuk artikel pertama Islam dan Barat oleh Sayyid Abu Al-Hassan 'Ali $\mathrm{Al}-\mathrm{Nadwi}{ }^{40}$ dan artikel kedua pula beliau menulis bersama Mohd Kamil bertajuk Epitermologi Islam Menurut Ibn Khaldun. ${ }^{41}$ Jadual 6: Jabatan / Fakulti Penulis Artikel

\begin{tabular}{|c|c|c|c|c|}
\hline No. & Jabatan/Fakulti & $\begin{array}{c}\text { Bil. } \\
\text { Penulis }\end{array}$ & $\begin{array}{c}\text { Penulis } \\
\text { per } \\
\text { Jabatan }\end{array}$ & $\begin{array}{c}\text { Peratus } \\
(\%)\end{array}$ \\
\hline 1 & Jab. Akidah dan Pemikiran Islam & 83 & 83 & 23.0 \\
\hline 2 & Jab. al-Quran dan al-Hadith & 32 & 32 & 8.8 \\
\hline 3 & Jab. Sejarah dan Tamadun Islam & 22 & 22 & 6.1 \\
\hline 4 & $\begin{array}{l}\text { Jab. Dakwah dan Pembangunan } \\
\text { Insan }\end{array}$ & 20 & 20 & 5.5 \\
\hline 5 & Jab. Syariah dan Ekonomi & 17 & 17 & 4.7 \\
\hline 6 & $\begin{array}{l}\text { Jab. Dakwah dan Kepimpinan, } \\
\text { UKM }\end{array}$ & 14 & 14 & 3.9 \\
\hline 7 & $\begin{array}{l}\text { Fak. Pengajian Kontemporari Islam, } \\
\text { UNISZA }\end{array}$ & 10 & 10 & 2.8 \\
\hline \multirow{2}{*}{8} & Jab. Siasah Syar'iyyah & \multirow{2}{*}{16} & 8 & 2.2 \\
\hline & Akad. Pengajian Islam, Nilam Puri & & 8 & 2.2 \\
\hline \multirow{2}{*}{9} & Jab. Fiqh dan Usul & \multirow{2}{*}{14} & 7 & 1.9 \\
\hline & Jab. Usuluddin dan Falsafah, UKM & & 7 & 1.9 \\
\hline \multirow{2}{*}{10} & $\begin{array}{l}\text { Jab. Pengajian al-Quran dan al- } \\
\text { Sunnah, UKM }\end{array}$ & \multirow{2}{*}{12} & 6 & 1.7 \\
\hline & $\begin{array}{l}\text { Jab. Pengajian Arab dan Tamadun } \\
\text { Islam, UKM }\end{array}$ & & 6 & 1.7 \\
\hline
\end{tabular}

39 Jurnal Usuluddin (Kuala Lumpur: Bahagian Pengajian Islam Universiti Malaya, 1997), bil.2.

40 Che Zarrina Binti Sa'ari, "Islam dan Barat oleh Sayyid Abu Al-Hassan 'Ali Al-Nadwi," Jurnal Usuluddin 11, Bil. 1 (2000), 187-200.

${ }^{41}$ Che Zarrina Binti Sa'ari dan Mohd Kamil Ab. Majid "Epitermologi Islam Menurut Ibn Khaldun”, Jurnal Usuluddin 12, bil. 2 (2000), 73-94. 


\begin{tabular}{|c|l|c|c|c|}
\hline \multirow{2}{*}{ No. } & \multicolumn{1}{|c|}{ Jabatan/Fakulti } & Bil. & $\begin{array}{c}\text { Penulis } \\
\text { per } \\
\text { Penulis }\end{array}$ & $\begin{array}{c}\text { Peratus } \\
\text { Jabatan }\end{array}$ \\
\hline \multirow{2}{*}{11} & Jab. Pengajian Umum, UIAM & \multirow{2}{*}{10} & 5 & 1.4 \\
\cline { 5 - 6 } & Jab. Syariah dan Pengurusan & & 5 & 1.4 \\
\hline 12 & 4 jabatan / fakulti & 16 & 4 & 4.1 \\
\hline 13 & 8 jabatan / fakulti & 24 & 3 & 6.6 \\
\hline 14 & 26 jabatan / fakulti & 52 & 2 & 14.4 \\
\hline 15 & 46 jabatan / fakulti & 46 & 1 & 13.0 \\
\hline
\end{tabular}

Seterusnya, jadual 6 menunjukkan jabatan atau fakulti tempat penulis bekerja. Perkiraan bilangan penulis berdasarkan namanama yang terdapat pada setiap artikel yang diterbitkan walaupun nama-nama tersebut ada yang berulang pada artikel yang berlainan atau bilangan penerbitan yang berlainan. Secara keseluruhan, Jabatan Akidah dan Pemikiran Islam, Akademi Pengajian Islam, Universiti Malaya (APIUM) merupakan jabatan yang paling banyak penulis artikel yang terlibat dalam Jurnal Usuluddin, iaitu sebanyak 83 orang (23.0\%). Diikuti oleh Jabatan al-Qur'an dan alHadith, Akademi Pengajian Islam, Universiti Malaya (APIUM) dengan jumlah 32 orang (8.8\%). Bagi jabatan yang ketiga banyak bilangan penulis artikel yang diterbitkan datang dari Jabatan Sejarah dan Tamadun Islam, Akademi Pengajian Islam, Universiti Malaya (APIUM) seramai 22 orang (6.1\%) manakala Jabatan Dakwah dan Pembangunan Insan, Akademi Pengajian Islam, Universiti Malaya (APIUM) seramai 20 orang (5.5\%).

Bilangan penulis artikel yang kelima terbanyak datang dari Jabatan Syariah dan Ekonomi, Akademi Pengajian Islam, Universiti Malaya (APIUM) dengan jumlah seramai 17 orang (4.7\%) dan diikuti kekerapan penulis oleh Jabatan Dakwah dan Kepimpinan Universiti Kebangsaan Malaysia (UKM) dengan jumlah 14 orang penulis artikel (3.9\%). Bagi Fakulti Pengajian Kontemporari Islam, Kolej Universiti Islam Sultan Zainal Abidin (KUSZA) (kini dikenali dengan UNISZA) seramai 10 orang penulis artikel $(2.8 \%)$ dalam senarai penulisan artikel Jurnal Usuluddin. Manakala Akademi Pengajian Islam, Universiti Malaya, Nilam Puri dan Jabatan Siasah Syar'iyyah, Akademi Pengajian Islam, Universiti Malaya (APIUM) masing-masing seramai 8 orang penulis artikel $(2.2 \%)$ menjadikan jumlah bagi kedua-dua Jabatan/ fakulti ini adalah 16 orang penulis artikel, iaitu 
(4.4\%). Bagi Jabatan Fiqh dan Usul, Akademi Pengajian Islam, Universiti Malaya (APIUM) dan Jabatan Usuluddin dan Falsafah, Universiti Kebangsaan Malaysia (UKM) masing-masing terdapat 7 orang penulis artikel (1.9\%) menjadikan jumlah penulis yang dihasilkan oleh kedua jabatan ini berjumlah 14 orang penulis (3.8\%).

Jabatan Pengajian al-Quran dan al-Sunnah, Fakulti Pengajian Islam, Universiti Kebangsaan Malaysia (UKM) dan Jabatan Pengajian Arab dan Tamadun Islam, Fakulti Pengajian Islam dari universiti yang sama masing-masing terdapat 6 orang penulis artikel (1.7\%) menjadikan jumlah keseluruhan adalah 12 orang penulis artikel (3.3\%). Manakala bagi Jabatan Pengajian Umum, Universiti Islam Antarabangsa Malaysia (UIAM) dan Jabatan Syariah dan Pengurusan, Akademi Pengajian Islam, Universiti Malaya (APIUM) masing-masing mempunyai 5 orang penulis artikel (1.4\%) menjadikan jumlah penulis artikel yang yang terlibat dari kedua-dua jabatan ini berjumlah 10 orang $(2.7 \%)$.

Bagi bilangan penulis yang mewakili setiap jabatan/ institusi hanya empat, tiga, dua dan seorang, hanya bilangan penulis sahaja dinyatakan, kerana bilangan penulis adalah kecil namun nama institusi pula terlalu banyak. Terdapat 4 jabatan/ fakulti yang mempunyai 4 orang penulis (1.1\%) menjadikan jumlah keseluruhan bagi keempat-empat jabatan / fakulti adalah seramai 16 orang penulis (4.4\%). Manakala Jabatan/ fakulti yang mempunyai 3 orang penulis yang menyumbang artikel $(0.6 \%)$ melibatkan 8 jabatan/ fakulti menjadikan jumlah keseluruhan penulis adalah seramai 24 orang penulis artikel (6.6\%). Seterusnya terdapat 2 orang penulis dari setiap jabatan/ fakulti yang melibatkan 26 buah fakulti merangkumi 52 orang penulis (14.4\%) serta bagi satu jabatan/ fakulti (0.3\%) setiap satu. Ada pun seorang penulis dari setiap Jabatan / fakulti adalah seramai 46 orang dari 46 jabatan / fakulti menjadikan nilai peratusan mereka adalah (13.0\%).

Jadual 7: Institusi / Universiti Penulis

\begin{tabular}{|c|l|c|c|c|}
\hline No. & \multicolumn{1}{|c|}{ Institusi/Universiti } & $\begin{array}{c}\text { Jumlah } \\
\text { Penulis }\end{array}$ & $\begin{array}{c}\text { Penulis } \\
\text { per Ins. }\end{array}$ & $\begin{array}{c}\text { Peratus } \\
(\%)\end{array}$ \\
\hline 1 & Universiti Malaya & 224 & 224 & 61.9 \\
\hline 2 & Universiti Kebangsaan Malaysia & 36 & 36 & 9.9 \\
\hline 3 & Univ. Islam Antarabangsa Malaysia & 19 & 19 & 5.2 \\
\hline
\end{tabular}




\begin{tabular}{|c|c|c|c|c|}
\hline No. & Institusi/Universiti & \begin{tabular}{|l} 
Jumlah \\
Penulis
\end{tabular} & $\begin{array}{l}\text { Penulis } \\
\text { per Ins }\end{array}$ & $\begin{array}{c}\text { Peratus } \\
(\%)\end{array}$ \\
\hline 4 & Universiti Sains Islam Malaysia & 13 & 13 & 3.6 \\
\hline 5 & Universiti Sultan Zainal Abidin & 11 & 11 & 3.0 \\
\hline \multirow{2}{*}{6} & Universiti Malaysia Sabah & \multirow{2}{*}{10} & 5 & 1.4 \\
\hline & Universiti Utara Malaysia & & 5 & 1.4 \\
\hline 7 & Institut Antarabangsa Tamadun & 4 & 4 & 1.1 \\
\hline \multirow{3}{*}{8} & Universiti Sains Malaysia & \multirow{3}{*}{9} & 3 & 0.8 \\
\hline & Kolej Univ. Islam Selangor & & 3 & 0.8 \\
\hline & Kolej Univ. Sains Teknologi M'sia & & 3 & 0.8 \\
\hline 9 & 2 institusi / universiti & 12 & 12 & 3.3 \\
\hline \multirow[t]{2}{*}{10} & 1 institusi / universiti & 24 & 24 & 6.6 \\
\hline & Jumlah & 362 & & 100 \\
\hline
\end{tabular}

Jadual 7 menunjukkan bilangan penulis artikel dari institusi pendidikan tinggi atau universiti yang terlibat dalam penulisan artikel dalam Jurnal Usuluddin lebih daripada 41 buah institusi / universiti dalam dan luar negara. Universiti Malaya (UM) menduduki tangga pertama dengan jumlah penulis tertinggi iaitu 224 orang penulis artikel (61.9\%). Kedua tertinggi diikuti oleh Universiti Kebangsaan Malaysia (UKM) dengan jumlah penulis artikel berjumlah 36 orang penulis (9.9\%), selepas UKM diikuti dengan kedudukan ketiga tertinggi oleh Universiti Islam Antarabangsa Malaysia (UIAM) seramai 19 penulis artikel (5.2\%).

Tempat keempat paling ramai penulis ialah Universiti Sains Islam Malaysia (USIM) iaitu seramai 13 orang penulis (3.6\%), manakala selepas USIM, diikuti oleh Universiti Sultan Zainal Abidin (UNISZA) seramai 11 penulis artikel (3.0\%). Seterusnya Universiti Malaysia Sabah (UMS) dan Universiti Utara Malaysia (UUM) masing-masing terdapat 5 orang penulis artikel (1.4\%) menjadikan jumlah keseluruhan adalah 10 orang penulis artikel (2.8\%). Adapun Institut Antarabangsa Tamadun Islam (ISTAC) hanya 4 orang penulis sahaja yang menyumbang artikel dalam Jurnal Usuluddin, iaitu (1.1\%).

Terdapat tiga buah universiti yang berkongsi tempat kelapan, iaitu Universiti Sains Malaysia (USM), Kolej Universiti Islam Antarabangsa Selangor (KUIS) dan Kolej Universiti Sains Teknologi Malaysia (KUSTEM) masing-masing terdapat 3 orang penulis artikel $(0.8 \%)$ menjadikan jumlah keseluruhan mereka adalah 24 orang penulis, menyamai (2.4\%). Manakala enam buah 
universiti lain pula, mempunyai 2 orang penulis artikel $(0.6 \%)$ setiap satu universiti menjadikan jumlah keseluruhan adalah 12 orang penulis. Menyamai (3.3\%) manakala bagi universiti yang mempunyai seorang penulis sahaja $(0.3 \%)$ melibatkan 24 buah universiti menjadikan nilai keseluruhan berjumlah 24 orang penulis $(6.6 \%)$.

Jadual 8: Negara Penulis

\begin{tabular}{|c|c|c|c|}
\hline No. & Negara & Bil. Penulis & Peratus $(\%)$ \\
\hline 1 & Malaysia & 345 & 95.0 \\
\hline 2 & Indonesia & 6 & 1.7 \\
\hline \multirow{4}{*}{3} & Qatar & 2 & 0.6 \\
\hline & Ghana & 2 & 0.6 \\
\hline & United Kingdom & 2 & 0.6 \\
\hline & Uganda & 2 & 0.6 \\
\hline \multirow{4}{*}{4} & Jordan & 1 & 0.3 \\
\hline & Emiriah Arab Bersatu & 1 & 0.3 \\
\hline & Thailand & 1 & 0.3 \\
\hline & Jumlah & 362 & 100.0 \\
\hline
\end{tabular}

Jadual 8 menunjukkan jadual negara asal atau tempat tinggal penulis dalam Jurnal Usuluddin sepanjang tahun 2000-2011 yang melibatkan 9 buah negara iaitu Malaysia, Indonesia, Cape Coast, United Kingdom (UK), Uganda, Jordan, Emiriat Arab Bersatu (UAE) dan Thailand. Penulis dari Malaysia berada dalam kedudukan tertinggi seramai 345 orang penulis (95.0\%). Diikuti dengan kedudukan kedua tertinggi oleh negara Indonesia yang mempunyai seramai 6 orang Penulis artikel (1.7\%).

Terdapat empat buah negara yang mempunyai penyumbang artikel yang sama iaitu hanya dua orang, negara-negara tersebut ialah Qatar, Cape Coast, United Kingdom (UK) dan Uganda dengan nisbah (0.6\%) menjadikan jumlah yang dihasilkan oleh keempat-empat negara tersebut seramai 8 orang penulis $(2.2 \%)$. Manakala bagi tiga negara iaitu negara Jordan, Emiriah Arab Bersatu (UAE) dan Thailand masing-masing menyumbang seorang penulis artikel sahaja (0.3\%) menjadikan jumlah keseluruhan penulis bagi ketiga-tiga negara tersebut seramai 3 orang penulis artikel $(0.9 \%)$. 
Carta 1: Bahasa Artikel

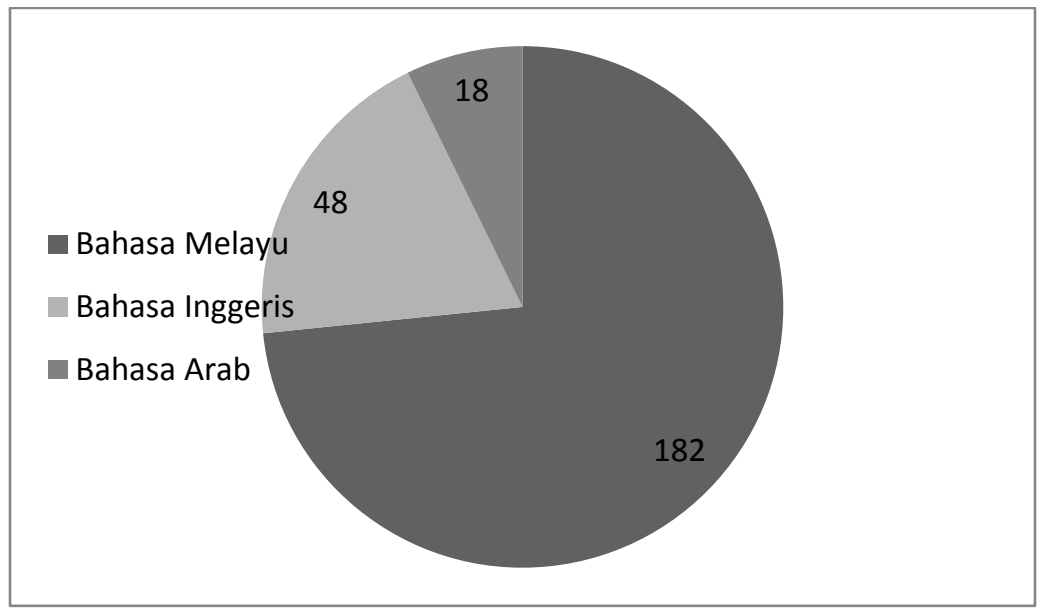

Carta 9 pula menunjukkan penggunaan bahasa artikel dalam Jurnal Usuluddin sepanjang tahun 2000-2011 yang mana hanya tiga bahasa digunakan iaitu Bahasa Melayu, Inggeris dan Arab. Dari analisis carta di atas, menunjukkan penggunaan Bahasa Melayu mendominasi bahasa penulisan artikel dalam Jurnal Usuluddin berbanding dua bahasa lain dengan jumlah tertinggi iaitu 182 buah artikel (74.0\%) berbanding dengan penggunaan bahasa Inggeris sebagai bahasa pilihan kedua dalam penulisan artikel dengan jumlah 48 buah artikel (19.0\%). Manakala Bahasa Arab menjadi pilihan ketiga bagi penulis artikel dalam Jurnal Usuluddin dengan jumlah 18 buah artikel sahaja (7.0\%).

\section{Perbincangan}

Berdasarkan jadual dan carta di atas, dapatlah disimpulkan bahawa Jurnal Usuluddin sepanjang tempoh yang dikaji memperlihatkan beberapa perkembangan positif dan telah mencapai satu aras penerbitan jurnal yang baik dan berwibawa. Antara perkara yang dapat disimpulkan ialah beberapa perkara berikut.

1. Kesungguhan sidang editor yang diketuai oleh beberapa ahli akademik yang berwibawa sejak awal penerbitannya hingga ke hari ini, telah berjaya membawa Jurnal Usuluddin ke satu tahap pencapaian yang membanggakan. Ianya bermula dari penerbitan sulung secara sekali setahun kepada penerbitan dwi tahunan dan terus berkembang secara konsisten. 
2. Sepanjang tempoh kajian, sebanyak 248 artikel telah diterbitkan dengan bilangan penulis seramai 362 orang. Ini menunjukkan bahawa para penulis Jurnal Usuluddin lebih gemar menulis secara sendirian berbanding penulisan bersama. Seramai 159 orang menulis artikel secara sendirian $64.0 \%$ dari keseluruhan penulis. Gambaran ini mungkin disebabkan oleh konsep artikel yang diterbitkan dalam Jurnal Usuluddin lebih banyak bersifat teoretikal berbanding kajian empirikal. Ataupun mungkin para penulis yang kebanyakan mereka terdiri dari sarjana pengajian Islam yang terbiasa menulis sendirian kerana mengikuti budaya penulisan sarjana Islam silam.

3. Terdapat beberapa faktor yang membentuk dominasi penulis Jurnal Usuluddin oleh lelaki berbanding perempuan. Antaranya ialah bilangan pensyarah senior lelaki di APIUM dan beberapa IPTA atau IPTS di Malaysia lebih ramai berbanding pensyarah perempuan. Nisbah ini lebih ketara dalam bidang pengajian Usuluddin berbanding bidang pengajian Islam yang lain.

4. Kebanyakan penggunaan muka surat bagi sesebuah artikel dalam Jurnal Usuluddin adalah antara 11-30 halaman, ianya membentuk nisbah $86.7 \%$ berbanding bilangan penggunaan muka surat yang lain. Ini kerana setiap artikel yang diterbitkan sering mengikut format penulisan tesis di APIUM, di mana setiap artikel terbentuk dari 5 bahagian, (1) pendahuluan, (2) perkembangan isu atau biografi tokoh, (3) perbincangan isu utama, (4) kesimpulan dan penutup dan (5) bibliografi. Pastinya lima bahagian yang dinyatakan itu amat munasabah memerlukan halaman muka surat antara 11-30 halaman bagi sesebuah artikel yang bersifat teoritikal atau empirikal.

5. Jadual 5 memperlihatkan bahawa penulis prolifik Jurnal Usuluddin adalah perempuan, beliau ialah Che Zarrina yang telah menyumbang sebanyak 15 artikel, selain itu didominasi penulis oleh para pensyarah APIUM, khususnya dari bahagian Pengajian Usuluddin melainkan Badlihisham dari UTM, Skudai. Ianya memperlihatkan seolah-olah Jurnal Usuluddin hanya untuk pensyarah APIUM sahaja walaupun ianya terbuka namun penyertaan dari penulis luar agak kecil.

6. Daripada keseluruhan penyumbang artikel dalam Jurnal Usuluddin, Jabatan Akidah dan Pemikiran Islam mendahului jabatan-jabatan lain dalam disiplin pengajian Usuluddin dengan 
$23.0 \%$ penulis dari jabatan itu. Manakala jabatan al-Quran dan alHadith di tempat kedua sebanyak $8.8 \%$ dan diikuti dengan Jabatan Sejarah dan Tamadun Islam sebanyak 6.1, Jabatan Dakwah dan Pembangunan Insan berada pada kedudukan keempat dengan peratusan $5.5 \%$ sahaja. Adalah wajar keempat-empat jabatan ini menduduki tempat tertinggi penyumbang tulisan kepada Jurnal Usuluddin kerana kesemua bidang kajian mereka berada dalam disiplin pengajian Usuluddin. Pastinya tulisan mereka lebih hampir dengan matlamat jurnal.

7. Dari aspek pengantarabangsaan pula, Jurnal Usuluddin masih jauh untuk dianggap sebagai sebuah jurnal antarabangsa secara seimbang. Kerana $9.5 \%$ artikel yang diterbitkan ditulis oleh penulis tempatan dan $1.7 \%$ peratus pula datang dari penulis Indonesia. Dengan peratusan yang besar negara penulis adalah dari Malaysia dan Indonesia, Jurnal Usuluddin lebih kelihatan sebagai sebuah jurnal bertaraf serantau bukan lagi benar-benar bertaraf antarabangsa. Gambaran ini disokong lagi dengan penggunaan bahasa Melayu yang lebih dominan, sebanyak $74 \%$ berbanding dua bahasa lain iaitu bahasa Inggeris dan Arab.

\section{Penutup}

Kesimpulannya, Jurnal Usuluddin sedang berada pada kedudukan yang betul dalam mengorak langkah untuk menjadi sebuah jurnal akademik berwasit, terindeks dalam indeks tersohor dan diterima di peringkat antarabangsa. Itu menjadikan Jurnal Usuluddin sebuah jurnal yang dihormati pastinya banyak perkara lagi yang perlu dipertingkatkan, antaranya ialah penggunaan Bahasa antarabangsa sama ada Bahasa Inggeris atau Arab haruslah seimbang atau nisbah $(4+3+3)$ agar lingkungan pembaca menjadi lebih besar dan sekaligus menjadikan citation oleh penulis lain dari artikel yang diterbitkan meningkat. Pengkaji berkeyakinan, semua penanda aras yang dijadikan ukuran untuk menjadikan Jurnal Usuluddin tersenarai dalam Indeks ISI atau Scopus dapat dicapai dalam masa terdekat. Keyakinan itu berasaskan kepada beberapa petunjuk yang terdapat pada jadual-jadual di atas, namun ianya masih perlu diperbaiki dan diperkemaskan.

Artikel ini juga masih terdapat banyak perkara lain yang tidak disentuh dalam menilai keseluruhan penerbitan jurnal, antaranya nisbah citation, jenis rujukan, jenis artikel, dan banyak lagi yang 
saya harapkan agar penyelidik lain cuba melengkapkannya dalam tulisan yang akan dating. Selain itu, saya ingin mengucapkan terima kasih kepada Saudari Saudah Abu Hassan kerana telah membantu saya dalam kerja-kerja mengumpul data-data kajian dan menganalisis data dalam bentuk peratusan.

\section{Rujukan}

"Sejarah Ringkas Penubuhan Jabatan," laman sesawang Jabatan Akidah dan Pemikiran Islam, dicapai 13 Mei 2019, http://japiapium.blogspot.com/

Ahmad Munawar Ismail. "Pembudayaan Ilmu Melalui Jurnal Akademik," laman sesawang Berita Harian Online, 30 Ogos 2018, dicapai 24 April 2019, https://www.bharian.com.my/rencana/komentar/2018/08/46775 6

Ali Muhammad. Metode Penyelidikan Ilmiah. Bandung: Penerbitan Sakti, 1985.

Al-Suyūṭī, Jalāl al-Dīn. Al-Takrīf fì Adāb al-Ta'līf. Kaherah: Maktabah al-Thurath al-Islāmī, 1987.

Asian Journal of Business and Accounting. Kuala Lumpur: Fakulti Perniagaan dan Perakaunan Universiti Malaya, 2008.

Berita Kejuruteraan. Lumpur: Fakulti Kejuruteraan Universiti Malaya, 1987.

Che Zarrina Binti Sa'ari dan Mohd Kamil Ab. Majid "Epitermologi Islam Menurut Ibn Khaldun," Jurnal Usuluddin 12, bil. 2 (2000), 73-94.

Che Zarrina Binti Sa'ari, "Islam dan Barat oleh Sayyid Abu AlHassan 'Ali Al-Nadwi," Jurnal Usuluddin 11, Bil. 1 (2000), 187-200.

Faisal@ Ahmad Faisal bin Abdul Hamid dan Saudah. "Sejarah Penerbitan Empat Jurnal Awal di APIUM," Jurnal alTamaddun 10, Bil. 1 (2015), 79.

International Journal of Mechanical and Materials Engineering. Kuala Lumpur: Jabatan Kejuruteraan Mekanikal Universiti Malaya, 2006.

ISLAMIKA. Kuala Lumpur: Akademi Islam Universiti Malaya, 1981.

Jernal Pentadbir. Kuala Lumpur: Kelab Pentadbiran Awam, Fakulti Ekonomi dan Pentadbiran Universiti Malaya, 1978. 
Jernal Sejarah. Kuala Lumpur: Jabatan Sejarah Universiti Malaya, 1975.

Journal of the Department of Engineering University of Malaya. Kuala Lumpur: Jabatan Kejuruteraan Universiti Malaya, 1962.

Journal of the Economic Society. Kuala Lumpur: Penerbit Universiti Malaya, 1960.

Jurnal Al-Bayan. Kuala Lumpur: Jabatan Al-Quran dan Al-Hadith Akademi Pengajian Islam Universiti Malaya, 2003.

Jurnal Al-Mukaddimah. Kuala Lumpur: Jabatan Sejarah dan Tamadun Islam, Akademi Pengajian Islam Universiti Malaya, 2013.

Jurnal Al-Tamaddun. Kuala Lumpur: Jabatan Sejarah dan Tamadun Islam, Akademi Pengajian Islam Universiti Malaya, 2005.

Jurnal Bahasa Moden. Kuala Lumpur: Pusat Bahasa Universiti Malaya, 1983.

Jurnal Figh. Kuala Lumpur: Jabatan Fiqh dan Usul, Akademi Pengajian Islam Universiti Malaya, 2004.

Jurnal Jabatan Pengajian Asia Tenggara Universiti Malaya.

Kuala Lumpur: Jabatan Pengajian Asia Tenggara Universiti Malaya, 1995.

Jurnal Pendidikan Islam. Kuala Lumpur: Fakulti Pendidikan Universiti Malaya,1984.

Jurnal Pengajian Asia Tenggara. Kuala Lumpur: Jabatan Pengajian Asia Tenggara Universiti Malaya, 1979.

Jurnal Pengajian India. Kuala Lumpur: Jabatan Pengajian India Universiti Malaya, 1983.

Jurnal Pengajian Melayu. Kuala Lumpur: Akademi Pengajian Melayu Universiti Malaya, 1989.

Jurnal Peradaban. Kuala Lumpur: Pusat Dialog Peradaban Universiti Malaya, 2008.

Jurnal Syariah. Kuala Lumpur: Fakulti Syariah Universiti Malaya, 1993.

Jurnal Usuluddin. Kuala Lumpur: Bahagian Pengajian Islam Universiti Malaya, 1997.

Jurnal Usuluddin. Kuala Lumpur: Fakulti Usuluddin Universiti Malaya, 1993.

Malaysia Journal of Economic Studies. Kuala Lumpur: Fakulti Ekonomi dan Pentadbiran Universiti Malaya, 1964. 
Masalah Pendidikan. Kuala Lumpur: Fakulti Pendidikan Universiti Malaya, 1965.

Md Sidin Ahmad Ishak. "Penerbitan Jurnal Ilmiah di Malaysia". Prosiding Mapim 1: Penerbitan Jurnal Ilmiah di Malaysia, Universiti Malaya, 1997.

MEDIUM:Majalah Elmiah (Kuala Lumpur: Akademi Islam Universiti Malaya, 1988).

Mohd Jajuli Abd. Rahman. "Penerbitan Jurnal: Pengalaman DBP". Prosiding Mapim 1: Penerbitan Jurnal Ilmiah di Malaysia, Universiti Malaya, 1997.

Roosfa Hashim, "Pembangunan Jurnal Ilmiah Malaysia 18472007”. Kuala Lumpur: Penerbit Universiti Malaya, 2011.

Sarjana. Kuala Lumpur: Fakulti Sastera dan Sains Sosial Universiti Malaya, 1981.

Sejarah: Jurnal Jabatan Sejarah Universiti Malaya. Kuala Lumpur: Jabatan Sejarah, Fakulti Sastera dan Sains Sosial, 1988.

Tirai Panggung. Kuala Lumpur: Pusat Kebudayaan Universiti Malaya, 1993.

Zainab Awang Ngah. "Malaysian Scholarly Journals: Their Visibility and Caracteristics," dalam Penerbitan Jurnal Ilmiah di Malaysia, ed. Md. Sidin Ahmad Ishal (Penyelenggara). Kuala Lumpur: Penerbit Universiti Malaya, t.t. 
Faisal, Perbincangan Bibliometrik 12 Tahun Penerbitan Jurnal Usuluddin 